Editorial

\title{
Introduction to user experience design for TV Apps
}

\section{A R T I C L E I N F O}

\section{Article history:}

Received 13 Febuary 2011

Revised 8 March 2011

Accepted 12 March 2011

Available online 31 March 2011

\section{Keywords:}

TV Apps

iTV

User experience

Television

Mobile TV

Social TV

\begin{abstract}
A B S T R A C T
In this introduction to the special issue of Entertainment Computing on the new TV landscape, we introduce interactive television (iTV) research as one of the pillars in the field of entertainment computing. Although entertainment computing has been associated mainly with video-games, there is also more than a couple of decades' research in computer applications for television. Contemporary infrastructures have been converging towards mature development platforms, but there are still several user experience issues in TV applications (TV Apps). Here, we explore significant contributions to interactive TV, and we provide directions for further research in user experience design for TV Apps.

(C) 2011 International Federation for Information Processing Published by Elsevier B.V. All rights reserved.
\end{abstract}

\section{Entertainment computing and TV Apps}

Interactive television has been a rather ambiguous term both in research and practice. Due to industry speculation most people have been expecting some kind of product, or service combination, which has not become popular for more than two decades, with a few notable exceptions (e.g., YouTube, TiVo). Besides a product, interactive TV (iTV) is a growing field of academic study. According to Cesar and Chorianopoulos [1]: "iTV research studies the interaction among users and video-clip based content, which is presented on networked multimedia computers". The EuroITV conference series is a platform which fosters this kind of research, and of which the EuroITV2009 edition has led to this special issue.

iTV research has built and extended upon established disciplines such as Human-Computer Interaction, Multimedia, and Communication Science. In many cases, contemporary research methods in iTV have been adopted from other disciplines. Moreover, iTV research focuses on those interdisciplinary cases that have guided researchers to leverage existing disciplinary methods, in order to address the development and use of TV Apps. Thus, the main topics of research and practice included input devices, visual user interfaces, and video mediated social communication. Among the key findings of early research, TV usage has been always considered a social activity [4]. Early iTV settings considered the remote control as the single input device, which imposed a number of restrictions on how groups of people can interact with content at home.

More recently, the boundaries between TV Apps as a set-top box based (or integrated) service in the living room versus interactive web-based television services (e.g., www.hulu.com) are blurring. In addition, video has been embedded in web pages and distributed in mobile devices, which have made TV Apps ubiquitous. Interactive television thus becomes a concept rather than a technology, which enables people to interact with television content on any device, be it a traditional television, a PC or a mobile phone. Moreover, the use of these different devices can be combined so variously sized screens are used simultaneously for a seamless interactive TV experience (the so-called 'threescreen experience').

TV Apps in Europe are normally associated with the provision of a return path from the user to the broadcaster. Since terrestrial television has been the predominant technology in many countries, setting up an efficient interaction channel to the content provider was a research topic of its own at the turning of the century. Several solutions such as SMS voting have been employed and accepted. A symmetrical return channel would allow bidirectional distribution of audiovisual content and would enable seamless videoconferencing. More recently, IPTV has provided a fully working return channel. Overall, many aspects of the TV experience are gradually mediated through a computer program, thus making possible any kind of manipulation or control of the TV content.

\section{State-of-the-art in TV App design}

The Electronic Program Guide (EPG) and the remote control have been the main focus of research and practice with regard to input and visual user interfaces. Mobile devices can be used as a secondary and personal display at home that can be used for controlling interactive television [2], and the convergence of mobile networks and interactive television. The latter research considers the convergence of devices not as a substitute ap- 
proach, but as an additive approach. An interesting research line is to study the handheld device screen as a secondary screen intended for personal information, which is addressed in the special issue article from Tsekleves, Whitham, Kondo and Hill. In this case, the distinction between shared devices (TV screen) and private screens at home (handheld device) can determine which information, depending on the nature of the information and the contextual situation of the user, is rendered where.

Information from other viewers can also be used to inform the user, or help to decide which content to select, e.g., by showing the most popular content for your circle of friends. On the other hand, if the users wish to switch from a relaxed content enriched communication session to an intense audio or text chat while watching television, a social TV system should be able to support it. Wheatley and Basapur expand this last concept, by using the television itself as a complete communication system, offering a technically and commercially viable solution for videoconferencing in the living room. Nevertheless, they concluded that such systems need to have specific control and privacy settings, in order to realize the full potential of TV based video telephony.

Regarding output devices, the industry has largely invested in two topics: high-definition television and mobile television. In particular, the availability of small broadband multimedia devices has motivated the study of content for mobile video formats [6]. There has also been a growing research interest on the usages of mobile television. Buchinger, Kriglstein, Brandt and Hlavacs provide a detailed account in this special issue on the different aspects of mobile television which have been studied in the past. One of the many results indicate that mobile television is an immediate and short activity, thus television programs have to be tailored specifically for this medium; not only in terms of resolution but as well in terms of length [7].

During the 90's, the increased availability of TV channels and content has become one of the main drivers for the development of technologies that assist content selection and navigation, such as the EPG and content personalization. Computer programs in digital set-top-boxes (STBs) may store and analyze a wide variety of interactions for every household. The availability of detailed user models makes possible a personalized approach for each individual, thus improving a medium, which has been characterized as mass and passive. Obrist, Moser, Alliez and Tscheligiargue in this special issue that new methods are needed for studying user behavior in a private, social and thus highly sensitive environment, applying this to the design and development of a novel EPG.

\section{Further reading and research}

As we showed in this editorial, interactive television research faces many challenges in a continually evolving technological landscape. While many new TV applications are being developed, especially with the advent of connected television sets, industry often neglects guidelines that help to avoid common pitfalls. We argue that more attention should be paid to these guidelines [3,5], which address important aspects to take into account in the development of TV Apps. This special issue offers a selection of four important contributions to this domain, each tackling a different research challenge.

The selection of papers also point at the future research opportunities we highlighted in this article. There are many TV Apps and some preliminary field studies (e.g., Yahoo! Connected TV widgets), a lot of research into the impact of social television on viewing behavior as well as the impact of user behavior on the design of social television systems is needed. Issues such as privacy and security, the tension between lean-back and lean-forward, optimal tools supporting remote as well as collocated communication, social recommendations, etc. need to be further looked at in more detail.

\section{References}

[1] P. Cesar, K. Chorianopoulos, The evolution of TV systems, content, and users toward interactivity, Foundations and Trends in Human-Computer Interaction 2 (4) (2009) 373-395.

[2] P. Cesar, D.C.A. Bulterman, D. Geerts, J. Jansen, H. Knoche, W. Seager, Enhancing social sharing of videos: fragment, annotate, enrich, and share, in: Proceedings of the ACM Conference on Multimedia, 2008, pp. 11-20.

[3] K. Chorianopoulos, User interface design principles for interactive television applications, International Journal of Human-Computer Interaction 24 (6) (2008) 556-573 (Taylor Francis).

[4] D. Gauntlett, A. Hill, TV Living: Television, Culture and Everyday Life, Routledge, 1999.

[5] D. Geerts, Dirk De Grooff, Supporting the social uses of television: sociability heuristics for social tv, in: Proceedings of the 27th International Conference on Human Factors in Computing Systems (CHI '09), ACM, New York, NY, USA, 2009, pp. 595-604

[6] H. Knoche, J.D. McCarthy, Design requirements for mobile TV, in: Proceedings of Mobile HCI, 2005, pp. 69-76.

[7] C. Södergard (Ed.), Mobile television - technology and user experiences, Report on the Mobile-TV Project, VTT Information Technology, 2003.

Konstantinos Chorianopoulos Ionian University, Department of Informatics, Tsirigoti Sq 7, 49100 Corfu, Greece

E-mail address: choko@ionio.gr

David Geerts K.U. Leuven, Centre for User Experience Research, Belgium 